\title{
Strain-induced Z-phase formation in a 9\% Cr-3\% Co martensitic steel during creep at elevated temperature
}

\author{
A. Fedoseeva*, I. Nikitin, N. Dudova, R. Kaibyshev \\ Belgorod National Research University, Pobeda 85, Belgorod 308015, Russia
}

\section{A R T I C L E I N F O}

\section{Keywords:}

Steel

Electron microscopy

Precipitation

Phase transformation

Orientation relationships

\begin{abstract}
A B S T R A C T
The size and distribution of $\mathrm{Cr}(\mathrm{V}, \mathrm{Nb}) \mathrm{N}$ (Z-phase) particles in a $9 \mathrm{Cr}-3 \mathrm{Co}-2 \mathrm{~W}-0.6 \mathrm{Mo}-0.1 \mathrm{Ni}-0.2 \mathrm{~V}-0.06 \mathrm{Nb}-0.1 \mathrm{C}$ $0.05 \mathrm{~N}-0.005 \mathrm{~B}$ steel subjected to creep rupture test during $11,151 \mathrm{~h}$ at $650{ }^{\circ} \mathrm{C}$ under an applied stress of $100 \mathrm{MPa}$ were studied. The replacement of $\mathrm{V}$-rich $(\mathrm{V}, \mathrm{Nb})(\mathrm{C}, \mathrm{N})$ carbonitrides by Z-phase was accelerated by plastic flow as suggested by a comparative analysis of these particles in different portions of crept specimen, namely, the grip section, the portion of uniform elongation, and the necked portions. Coarse "hybrid" Z-phase particles evolved throughout the crept specimen by an in situ transformation mechanism. The strain-induced Z-phase nucleated on the V-rich $(\mathrm{V}, \mathrm{Nb})(\mathrm{C}, \mathrm{N}) /$ ferrite interfaces, leading to the formation of numerous Z-phase particles with dimensions less than $50 \mathrm{~nm}$ in the necked portion.
\end{abstract}

\section{Introduction}

The creep strength of 9-12\% Cr martensitic steels, which are considered as advanced heat resistant materials for fossil power plants, is provided by tempered martensite lath structure (TMLS) strengthened by dispersed particles including $\mathrm{Cr}_{23} \mathrm{C}_{6}$-type carbides and MX-type carbonitrides (here $\mathrm{M}$ means $\mathrm{V}$ and/or $\mathrm{Nb}$, and $\mathrm{X}$ represents $\mathrm{C}$ and/or $\mathrm{N}$ ) [1]. The former particles locate at various boundaries/subboundaries and stabilize TMLS owing to Zener pinning pressure, while the latter particles are uniformly distributed throughout and provide effective dispersion strengthening [1-8]. Two-phase separation of MX particles into V-rich and Nb-rich particles provides their high coarsening resistance during creep at elevated temperatures [4-7,9-11]. The MX carbonitrides have a $\mathrm{B} 1(\mathrm{NaCl})$ type crystal structure with lattice parameter of $0.414-0.447 \mathrm{~nm}$ depending on their chemical compositions $[1,6,12-18]$.

Nanoscale MX carbonitrides can be replaced by coarse $\mathrm{Cr}(\mathrm{V}, \mathrm{Nb}) \mathrm{N}$ (Z-phase) particles under long-term aging or creep, leading to a detrimental effect on the creep strength [10-18]. The Cr content in Z-phase and MX carbonitrides is about 33 at $\%$ and less than 18 at $\%$, respectively [15]. The MX transformation into Z-phase is accompanied by a depletion of the MX particles with C and the enrichment with $\mathrm{Cr}$ [10,13-15]. Two types of crystal lattice have been reported for Z-phase in 9-12\% Cr steel [13-15]. The cubic $\mathrm{B} 1 \mathrm{(NaCl})$ type crystal structure with a lattice parameter of $\sim 0.404 \mathrm{~nm}$ is the intermediate metastable phase, which can transform to the thermodynamically stable phase exhibiting a tetragonal crystal structure with lattice parameters of $a=0.286 \mathrm{~nm}$ and $c=0.739 \mathrm{~nm}$ [13-15]. It is worth noting that the lattice parameter of $a$ depends on the chemical composition of Z-phase [15]. The formation of Z-phase particles occurs through in situ transformation of the crystal lattice of MX carbonitrides leading to a continuous flux of $\mathrm{Cr}$ atoms from the ferritic matrix into these particles. When $\mathrm{Cr}$ diffuses into the MX particles, the composition gradually changes leading to cubic Zphase. Then, the $\mathrm{V}, \mathrm{N}$ and $\mathrm{Cr}$ atoms slowly order themselves into $\mathrm{VN}$ and a $\mathrm{Cr}$ layers; thus, the tetragonal crystal structure appears. In 9-12\% $\mathrm{Cr}$ steels, both crystal structures were revealed to be present in the Zphase, and this ordering occurred at $600-650^{\circ} \mathrm{C}$ [13-15]. This continuous (in situ) transformation of MX into Z-phase occurs at a very low rate and can result in the formation of "hybrid" Z-phase crystal structure, in which cubic and tetragonal crystal structures coexist in the core and surface regions, respectively $[9,13-15,19]$. The detrimental effect of Z-phase on the creep strength of high-Cr steels is attributed to Zphase particles with tetragonal crystal structure, which quickly coarsen consuming finely dispersed MX particles that have not transformed to Z-phase. As a result, a small number of coarse Z-phase particles replaces numerous nanoscaled MX carbonitrides, which provided the superior creep resistance.

A high $\mathrm{Cr}$ content in the ferritic matrix promotes the Z-phase formation, its formation rate in $12 \mathrm{wt} \% \mathrm{Cr}$ steels is higher by a factor of $20-40$ than that in $9 \% \mathrm{Cr}$ steels $[13-17,19,20]$. Moreover, relatively small Z-phase particles have only been observed in 9\% Cr steels $[4,5,7,10,21]$, whereas coarse Z-phase particles have been frequently detected in $12 \% \mathrm{Cr}$ steels after long-term aging $[13,15]$. As a result, the formation of Z-phase deteriorates creep resistance of $11-12 \mathrm{wt} \% \mathrm{Cr}$

\footnotetext{
* Corresponding author.

E-mail address: fedoseeva@bsu.edu.ru (A. Fedoseeva).
} 


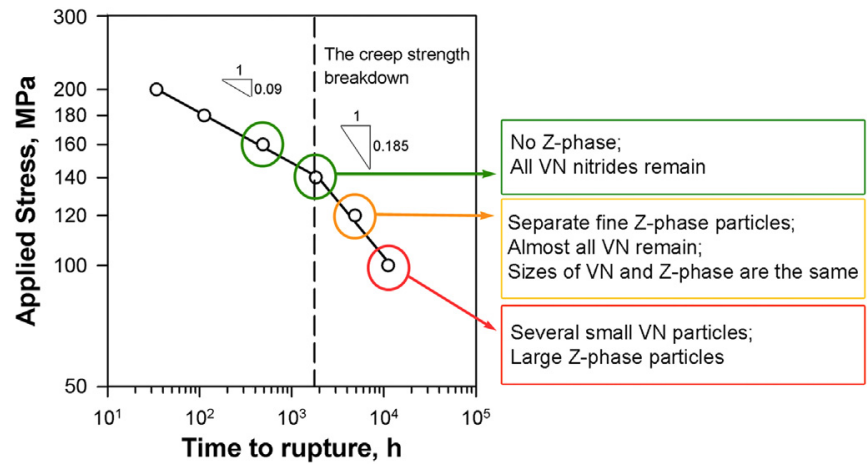

Fig. 1. Creep strength breakdown in the present $9 \% \mathrm{Cr}$ steel [11] and a dispersion of MX carbonitrides in the necks of the ruptured samples.

steels $[14,15,20,22]$, whereas creep strength breakdown in $9 \% \mathrm{Cr}$ steels is not related with the MX to Z-phase transformation [11,12,19,21]. The deterioration of creep strength has been shown to appear two or more times earlier than this phase transformation starts to occur (Fig. 1) in a $9 \% \mathrm{Cr}-3 \%$ Co- $2 \%$ W steel $[11,12]$. No formation of Z-phase particles occurs in $9 \% \mathrm{Cr}$ steels after short-term creep [11,12]. In addition, no difference in the dimensions of the Z-phase particles and V-rich MX carbonitrides was found, and the volume fraction of the Z-phase particles was negligible at low stresses in $9 \% \mathrm{Cr}$ steels. Thus the detrimental effect of Z-phase on creep strength of $9 \% \mathrm{Cr}$ steel is not obvious.

Modern 9\% Cr steels contain W and Co additions that slow down the diffusion process during creep or long-term aging. However, effect of these alloying elements on the Z-phase formation is opposite. Tungsten hinders the transformation of V-rich MX carbonitrides to Z-phase $[12,21]$, whereas cobalt accelerates this transformation [15]. The Zphase formation in 9\% Cr-3\% Co steels with $2 \%$ and $3 \% \mathrm{~W}$ has been observed only after long-term creep $[11,20]$. It is known $[22,23]$ that the presence of $0.28 \mathrm{wt} \% \mathrm{Ni}$ in P91-type steel promotes the formation of Z-phase and elimination of MX particles during creep. In addition, this element accelerates coarsening of $\mathrm{M}_{23} \mathrm{C}_{6}$ carbides that has a detrimental effect on creep strength $[1,22]$. As a result, new grades of $9 \% \mathrm{Cr}$ steels contain very low $\mathrm{Ni}$ [1]. The Z-phase is pure nitride, and decreasing $\mathrm{C}$ and increasing $\mathrm{N}$ promote its formation [15]. The Z-phase was found after long-term aging in a 9\% Cr-3\% Co steel with low C content and high $\mathrm{N}$ content [6]. It can be noted that $\mathrm{Cr}_{2} \mathrm{~N}$ particles may transform into Z-phase under long-term aging of $11 \% \mathrm{Cr}$ steels [24]. However, either no $\mathrm{Cr}_{2} \mathrm{~N}$ particles precipitate during tempering in $9 \% \mathrm{Cr}$ steels or the volume fraction of these precipitates is negligible small $[1,4,5,11,21,25] . \mathrm{Cr}_{2} \mathrm{~N}$ particles contain about $70 \mathrm{at} \% \mathrm{Cr}$, and their precipitation during tempering in $12 \% \mathrm{Cr}$ steels with high $\mathrm{N}$ content may suppress or retard the precipitation of Z-phase under creep conditions [15]. Thus, the mechanism and behavior of the MX to Z-phase transformation depend significantly on the chemical composition of high-Cr martensitic steels. The different kinetics of the MX to Z-phase transformation that is attributed to $\mathrm{Cr}$ content variation may lead to remarkably different effect of this transformation on creep strength breakdown of $9-12 \%$ Cr steels $[15,16,26]$.

The main aim of this work is to consider the mechanisms of Z-phase formation in a $9 \% \mathrm{Cr}-3 \% \mathrm{Co}-2 \% \mathrm{~W}$ steel and specific attention is paid to the effect of creep strain on the replacement of MX carbonitrides by Zphase particles.

\section{Experimental}

A $3 \mathrm{wt} \%$ Co-modified P92-type steel with chemical composition (in wt $\%$ ) of $\mathrm{Fe}$ (bal.)-0.12C-9.5Cr-3.2Co-2.0W-0.45Mo-0.06Si-0.2Mn$0.1 \mathrm{Ni}-0.2 \mathrm{~V}-0.06 \mathrm{Nb}-0.05 \mathrm{~N}-0.005 \mathrm{~B}$ was prepared by air melting. The steel was solution treated at $1050{ }^{\circ} \mathrm{C}$ for $30 \mathrm{~min}$, air cooled, and tempered at $750^{\circ} \mathrm{C}$ for $3 \mathrm{~h}$. A cylindrical specimen with a gauge length of
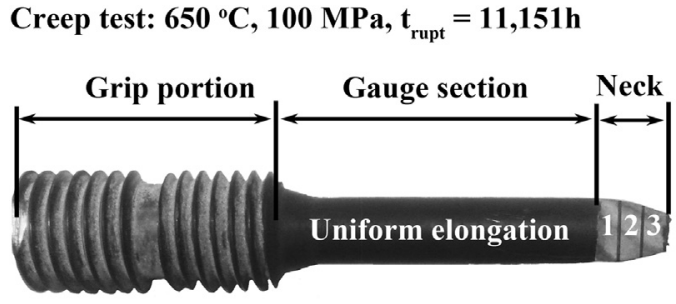

Fig. 2. Image of the crept sample at $650{ }^{\circ} \mathrm{C}$ and $100 \mathrm{MPa}$.

Table 1

Reduction in area in the different sections of crept sample at $650^{\circ} \mathrm{C}$ and $100 \mathrm{MPa}$

\begin{tabular}{llllll}
\hline Sections of sample & Grip & $\begin{array}{l}\text { Gauge (uniform } \\
\text { elongation) }\end{array}$ & \multicolumn{2}{l}{ Neck } & \\
\cline { 3 - 6 } & & Zone \#1 & Zone \#2 & Zone \#3 \\
\hline $\begin{array}{c}\text { Reduction in area, } \\
\psi, \%\end{array}$ & 0 & 9 & $9-11$ & $11-21$ & $21-45$ \\
\hline
\end{tabular}

$100 \mathrm{~mm}$ and diameter of $10 \mathrm{~mm}$ was crept until rupture at $650{ }^{\circ} \mathrm{C}$ under the applied stress of $100 \mathrm{MPa}$ using an ATS2330 lever arm machine. The rupture time was $11,151 \mathrm{~h}$. The rupture elongation and reduction in area were $5.5 \%$ and $45 \%$, respectively.

The structural investigations were carried out separately in specimen portions experienced different local creep strains, namely, the grip portion, the portion of uniform elongation, and three portions within the neck (Fig. 2 and Table 1). The microstructural characterization was performed using a JEM-2100 transmission electron microscope (TEM) equipped with an INCA energy dispersive X-ray spectroscope (EDS). The TEM specimens were prepared by electro-polishing at room temperature using a solution of $10 \%$ perchloric acid in glacial acetic acid with Struers Tenupol-5 polisher. In addition, carbon extraction replicas were used to clarify the chemical composition of dispersoids to avoid matrix effects when obtaining EDS spectra. Before replication, the specimen surface was mechanically polished followed by etching with a solution of $10 \%$ hydrochloric acid in ethanol. The size distribution and mean radius of the secondary phase particles were estimated by counting of $50-100$ particles on at least 15 arbitrarily selected typical TEM images for each data point. The precipitates were identified by a concurrent analysis of the EDS measurements and electron diffraction patterns. Other details of structural characterization and specimen preparation were reported previously $[4-6,10-12,21,25]$.

\section{Results}

\subsection{MX carbonitrides after tempering}

The microstructure of the 3\% Co-modified P92 steel after normalization and tempering at $750{ }^{\circ} \mathrm{C}$ has been detailed in previous papers $[11,12,26]$, and the parameters of TMLS and dispersed particles are summarized in Tables 2-4. It should be noted here briefly that the globular $\mathrm{M}_{23} \mathrm{C}_{6}$ carbides with an average size of $90 \mathrm{~nm}$ locate mainly at various grain/subgrain boundaries including the prior austenite grain (PAG) boundaries and lath boundaries, while the MX carbonitrides are uniformly distributed within the laths (Fig. 3). The latter ones can be categorized in two groups $[1,9,25]$, namely, a group of V-rich MX with a plate-like shape with the aspect ratio of $\sim 2.5$ and the mean longitudinal size of $20 \mathrm{~nm}$ and a group of round-shape Nb-rich MX

Table 2

Structural parameters of the $3 \%$ Co-modified P92 steel after tempering at $750{ }^{\circ} \mathrm{C}$.

\begin{tabular}{llllll}
\hline$D_{\mathrm{PAG}}, \mu \mathrm{m}$ & $D_{\text {subgrains }}, \mu \mathrm{m}$ & $\rho \perp \times 10^{14} \mathrm{~m}^{-2}$ & $d_{\mathrm{M} 23 \mathrm{C} 6}, \mathrm{~nm}$ & $d_{\mathrm{VX}}, \mathrm{nm}$ & $d_{\mathrm{NbX}}, \mathrm{nm}$ \\
\hline $11 \pm 1$ & $0.40 \pm 0.15$ & $2.0 \pm 0.1$ & $90 \pm 20$ & $20 \pm 5$ & $40 \pm 5$ \\
\hline
\end{tabular}


Table 3

Chemical composition (in wt\%) and average size of MX carbonitrides after tempering measured from replicas by EDS with TEM.

\begin{tabular}{|c|c|c|c|c|c|c|}
\hline \multirow[t]{2}{*}{ Phase } & \multicolumn{5}{|c|}{ Chemical composition, wt $\%$} & \multirow[t]{2}{*}{ Average size, $\mathrm{nm}$} \\
\hline & $\mathrm{V}$ & $\mathrm{Nb}$ & $\mathrm{Cr}$ & $\mathrm{Fe}$ & $\mathrm{W}$ & \\
\hline Nb-rich MX & 2.80 & 79.09 & 2.62 & 2.04 & 13.45 & $40 \pm 5$ \\
\hline V-rich MX & 62.05 & - & 27.95 & 10.00 & - & $20 \pm 5$ \\
\hline
\end{tabular}

Table 4

Effect of aging time on dimensions of V-rich MX carbonitrides.

\begin{tabular}{llll}
\hline State & Length, nm & Width, nm & Aspect ratio \\
\hline Initial state & 30 & 14 & 2.2 \\
Long-term aging for 11,151 h & 50 & 34 & 1.5 \\
\hline
\end{tabular}

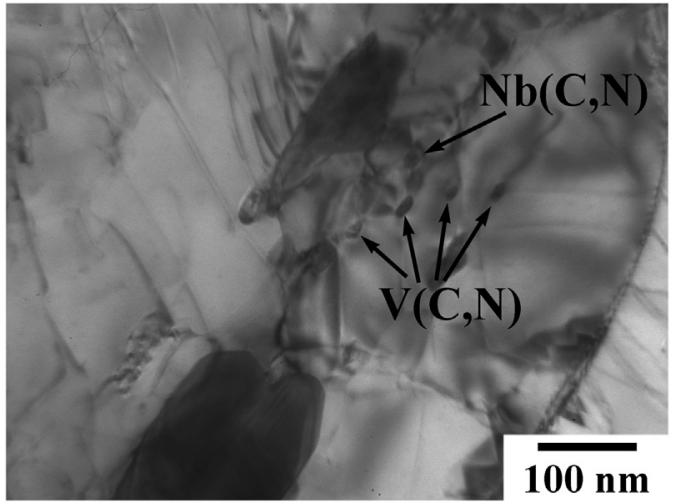

Fig. 3. TEM image of V-rich and Nb-rich MX carbonitrides after tempering at $750{ }^{\circ} \mathrm{C}$ for $3 \mathrm{~h}$.

carbonitrides with the average size of $\sim 40 \mathrm{~nm}$ (Fig. 3, Tables 3 and 4). The different morphology and chemical composition of Nb-rich and Vrich MX carbonitrides is attributed to the different nucleation mechanisms. Nb-rich MX dispersoids precipitate on dislocations during self-tempering or tempering at $\mathrm{T} \leq 400^{\circ} \mathrm{C}$, whereas V-rich carbonitrides nucleate homogeneously in the ferritic matrix under tempering in the $650-750^{\circ} \mathrm{C}$ temperature interval $[12,25]$. It is worth noting that a small number of coarse Nb-rich MX carbonitrides is observed at the PAG boundaries [25]. Those were probably precipitated during solidification.

\section{2. $M X$ carbonitrides after long-term aging}

The long-term aging is accompanied with a slow coarsening of dispersed particles. The average sizes of V-rich and Nb-rich MX carbonitrides increase to 70 and $80 \mathrm{~nm}$, respectively, in the grip portion of the crept specimen (Tables 4, 5). The Nb-rich carbonitrides remain their equiaxed shape, whereas the V-rich carbonitrides are dimensionally unstable upon long-term aging. The aspect ratio of V-rich MX dispersoids decreases to 1.5 during aging for $11,151 \mathrm{~h}$ (Table 4). The shape of these particles tends to approach round one under long-term aging.

Table 5

Chemical composition measured from replicas by EDS with TEM and average size of MX carbonitrides after long-term aging in the grip portion of sample.

\begin{tabular}{llllll}
\hline \multirow{2}{*}{ Phase } & \multicolumn{2}{l}{ Chemical composition, wt\% } & & \multirow{2}{*}{ Average size, nm } \\
\cline { 2 - 4 } & $\mathrm{V}$ & $\mathrm{Nb}$ & $\mathrm{Cr}$ & $\mathrm{Fe}$ & \\
\hline Nb-rich MX & 7.54 & 89.98 & 2.48 & - & $80 \pm 5$ \\
V-rich MX & 73.45 & 7.08 & 16.91 & 3.29 & $70 \pm 5$ \\
\hline
\end{tabular}

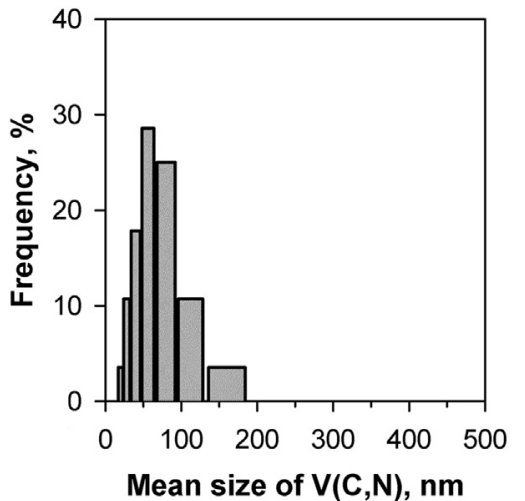

Fig. 4. Size distribution of V-rich $\mathrm{MX}$ carbonitrides after long-term aging at $650{ }^{\circ} \mathrm{C}$ for $11,151 \mathrm{~h}$.

The size distribution of V-rich carbonitrides is shown in Fig. 4. The fine particles with a size of $40 \mathrm{~nm}$ co-exist with coarse particles with a size of $150 \mathrm{~nm}$. The change in the chemical composition of V-rich MX particles is characterized by increase in the $\mathrm{V}$ and $\mathrm{Nb}$ contents and a decrease in the $\mathrm{Cr}$ content (Table 5). In contrast, the chemical composition of Nb-rich MX carbonitrides does not change remarkably (Table 5). Therefore, decreasing the $\mathrm{Cr}$ content in V-rich carbonitrides should suppress the Z-phase formation.

\subsection{MX carbonitrides after long-term creep}

The dimension and chemical composition of Nb-rich MX particles after long-term aging and creep are nearly the same. The dispersed Nbrich carbonitrides are apparently the same in various portions of the crept specimen. Therefore, the strain-induced coarsening of Nb-rich MX particles and/or the transformation of Nb-rich MX into Z-phase scarcely occurred during the creep test.

On the other hand, the strain-induced growth of V-rich MX particles and their transformation into Z-phase occur under creep conditions. In the specimen portion of uniform elongation corresponding to a reduction in area of $9 \%$, the coarse MX particles enriched by $\mathrm{Cr}$ ( $42 \mathrm{wt} \%$ ), $\mathrm{V}$ (30 wt $\%$ ) and $\mathrm{Nb}(22 \mathrm{wt} \%$ ) with an average size of $200 \mathrm{~nm}$ are observed (Fig. 5). The particles with irregular shapes are identified as Z-phase (CrVN) with a tetragonal lattice. Besides these large Z-phase particles, V-rich MX particles with an average size of $70 \mathrm{~nm}$ are also observed. The number densities of Z-phase and MX particles are nearly the same in the portion of uniform elongation (Table 6).

In the necked portion \#1, the Z-phase fraction exceeds the fraction of V-rich MX dispersoids in about 1.5 times (Table 6). The chemical composition and dimensions of Z-phase particles in the necked portion \#1 are the same with those in the portion of uniform elongation. In both these regions, "hybrid" Z-phase particles can be observed (Fig. 6). These "hybrid" particles exhibit the V-rich and Cr-poor core with a B1 cubic lattice and the Cr-rich rim with a tetragonal lattice (Fig. 6a), indicating the transformation of the V-rich particles into Z-phase by $\mathrm{Cr}$ diffusion.

Necking provides localization of plastic deformation, and local creep stresses increase that leads to the rise of the fraction of V-rich particles transformed to Z-phase up to almost complete disappearance of the fine VX carbonitrides (Figs. 7 and 8). In the necked portion \#2 corresponding to a reduction in area of $11-20 \%$, an average size of the Z-phase particles comprises $150 \mathrm{~nm}$, while the VX: Z-phase ratio decreased to 1: 2.3 (Table 6). Only a few fine V-rich MX carbonitrides with an average size of about $70 \mathrm{~nm}$ can be observed in the necked portion \#3 corresponding to a reduction in area of $21-45 \%$. The Z-phase particles with irregular shapes and the mean size of approximately $270 \mathrm{~nm}$ are dominant (Fig. 8). Therefore, the complete transformation of MX carbonitrides into Z-phase followed by the growth of Z-phase particles 

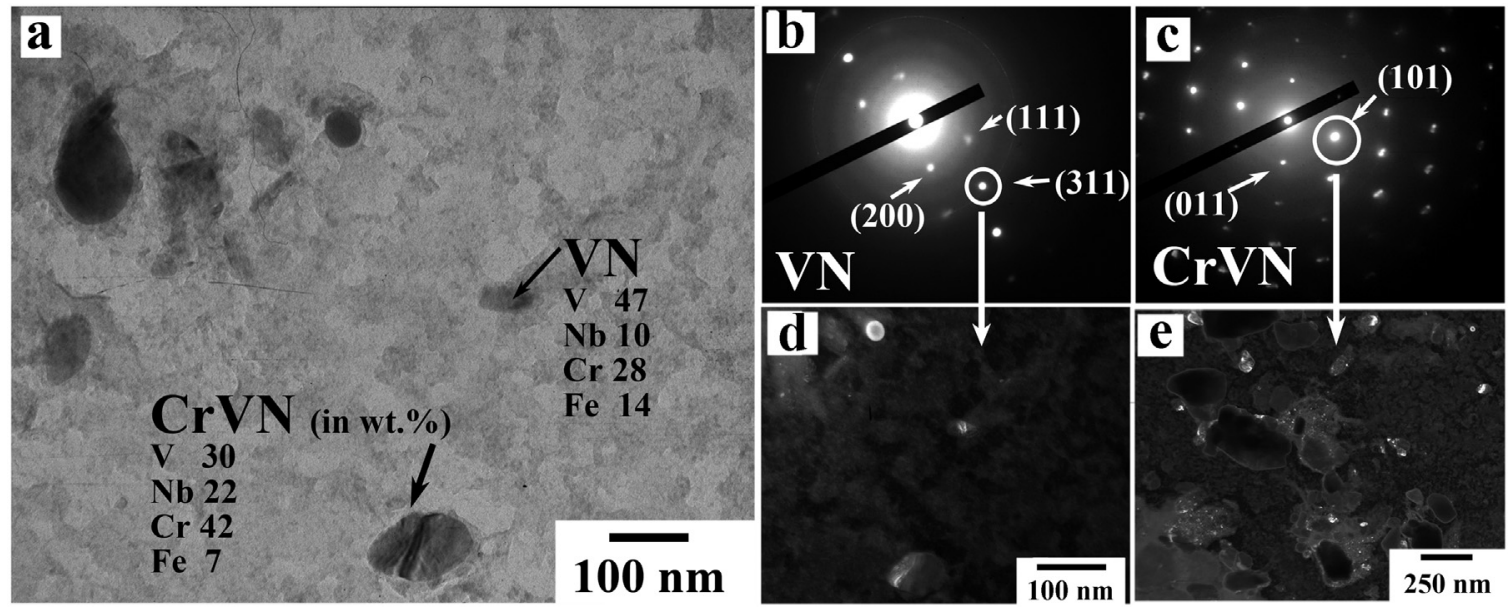

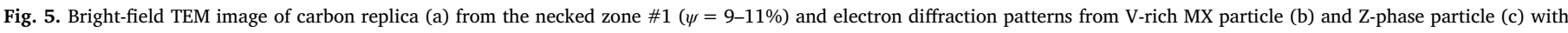

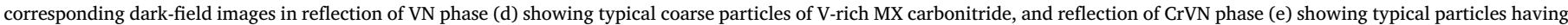
full Z-phase composition.

Table 6

Particle ratio of VN: $\mathrm{CrVN}$ in the different sections of crept sample.

\begin{tabular}{lllll}
\hline \multirow{2}{*}{ Ratio } & Gauge section & \multicolumn{2}{l}{ Neck section } & \\
\cline { 3 - 5 } & & Zone \#1 & Zone \#2 & Zone \#3 \\
\hline VN: CrVN & $1: 1$ & $1: 1.5$ & $1: 2.3$ & $1: 9$
\end{tabular}

resulting in the full replacement of the nanoscale V-rich MX carbonitrides by the coarse Z-phase particles during long-term creep can be considered as a creep strain-assisted phenomenon.

\subsection{Size distribution of V-rich $M X$ carbonitrides and Z-phase particles}

In the portion of uniform elongation (Fig. 9(a)), the coarse V-rich MX particles with sizes larger than $100 \mathrm{~nm}$ disappear and the amount of fine V-rich MX particles with dimensions below $40 \mathrm{~nm}$ decreases remarkably. The corresponding size distribution of V-rich MX carbonitrides is much narrower as compared to that in the grip portion (aged condition). It is apparent that the strain-induced coarsening of the fine V-rich MX particles with sizes less than $40 \mathrm{~nm}$ leads to an increase in the fraction of particle sizes of 50-100 $\mathrm{nm}$. On the other hand, the coarse Vrich MX carbonitrides with sizes above $100 \mathrm{~nm}$ are highly susceptible to the strain-induced transformation into Z-phase. Hence, such large Vrich MX dispersoids are not observed in the creep strain-affected portions. The size distribution of V-rich MX particles in the necked portion \#1 is nearly the same with that in the portion of uniform elongation (Fig. 9(b)). Further increase in the creep stress due to increased local creep strain leads to disappearance of V-rich MX particles with sizes below $40 \mathrm{~nm}$ (Fig. 9(c)). In the necked portion \#3, the size distribution of V-rich MX particles is characterized by a sharp peak for particle sizes of 70-90 nm (Fig. 9(d)). This suggests that the V-rich MX particles of
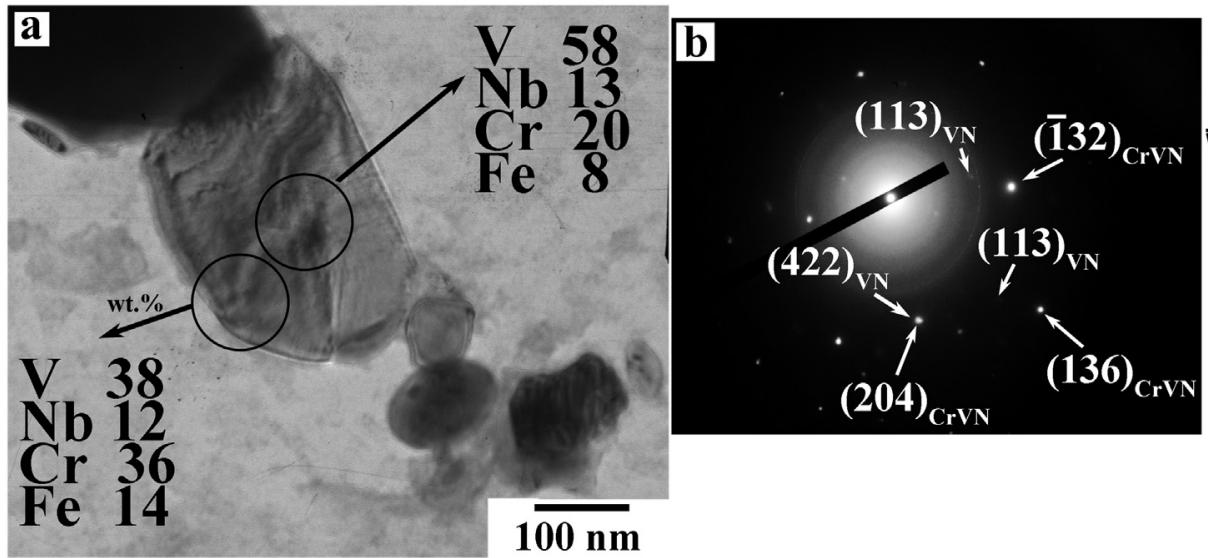

(c)

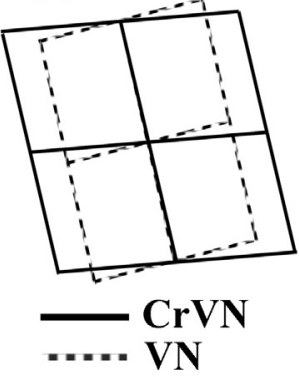

(d)

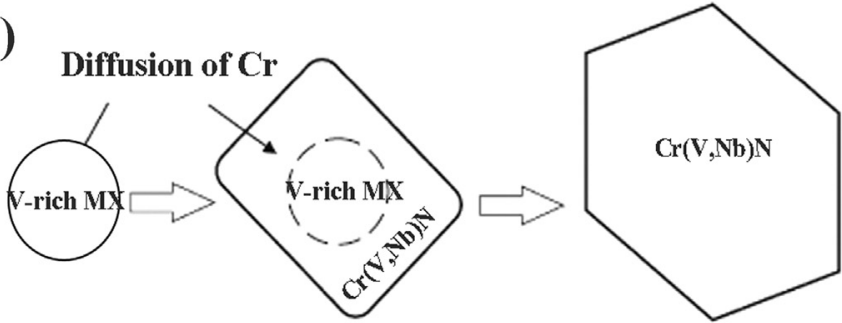

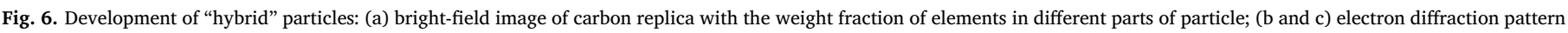
showing reflexes from CrVN and VN phases; (d) schematically illustrated sequence of the "hybrid" particle formation taken from [10]. 

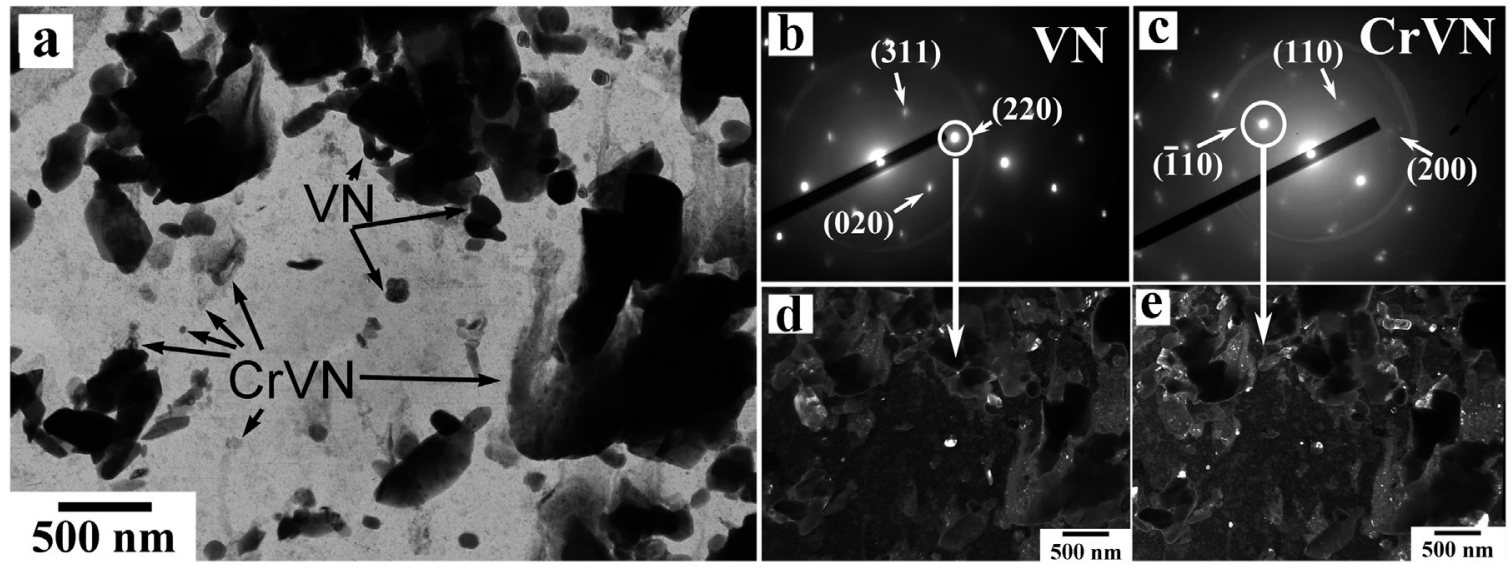

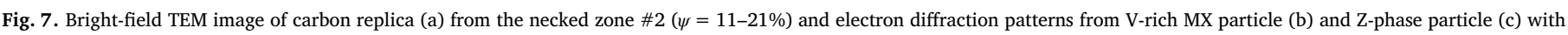
corresponding dark-field images in reflection of VN phase (d) and CrVN phase (e).

$70-90 \mathrm{~nm}$ in size are the most stable against the transformation into Zphase.

Non-uniform size distributions of Z-phase particles with nearly round shapes are observed in the portion of uniform elongation and necked portion \#1 (Fig. 9(e) and (f)). The coarse Z-phase particles with "hybrid" structure co-exist with V-rich MX carbonitrides (Fig. 6). The absence of the Z-phase particles with the size less than that of the V-rich MX particles indicates that the Z-phase formation initially occurs by enrichment of the surface layers of V-rich particles with $\mathrm{Cr}$ atoms followed by continuous transformation of cubic lattice into tetragonal lattice.

An increase in the creep stress due to increased local creep strain increases significantly the Z-phase fraction and decreases the number density of V-rich MX carbonitrides (Table 6, Figs. 6, 8 and 9). In the necked portion \#2, the fraction of Z-phase particles is 0.7 among all the particles enriched by $\mathrm{V}, \mathrm{Nb}, \mathrm{Cr}$ and $\mathrm{Fe}$. The main feature of the Z-phase particle size distribution is the appearance of Z-phase particles with the dimensions above $500 \mathrm{~nm}$ and a rather large fraction of relatively fine Z-phase particles with sizes of about $50 \mathrm{~nm}$ (Fig. 9(g)). The latter particles are characterized by a uniform tetragonal structure and $\mathrm{Cr}$ content above $30 \mathrm{wt} \%$ in the entire particle (Fig. 10). Moreover, the fine Zphase particles with the sizes ranging from $10 \mathrm{~nm}$ to $25 \mathrm{~nm}$ are observed (Fig. 9(g)). As a result, the bimodal size distribution of Z-phase particles with two peaks corresponding to $50 \mathrm{~nm}$ and $350 \mathrm{~nm}$ are observed (Fig. 9(g)).

In the necked portion $\# 3$, the fine Z-phase particles almost completely replaced the V-rich MX carbonitrides with sizes less than $50 \mathrm{~nm}$ (Fig. 9(d)). The fraction of Z-phase particles among all particles enriched by V, Nb, $\mathrm{Cr}$ and Fe reaches 0.9 (Table 6). A well-defined peak corresponding to the Z-phase particle size of $220 \mathrm{~nm}$ appears (Fig. 9(h)). The Z-phase particles with irregular shapes and the mean size up to $800 \mathrm{~nm}$ are frequently observed concurrently with the numerous Z-phase dispersoids with the sizes ranging from $12 \mathrm{~nm}$ to $50 \mathrm{~nm}$. Therefore, the local creep strain promotes both the coarsening of large Z-phase particles and the formation of fine Z-phase particles.

\section{Discussion}

Sawada et al. $[22,23]$ have suggested that an increase in the $\mathrm{Ni}$ content promotes the replacement of MX carbonitrides by Z-phase during creep. The present results suggest that the local creep strain and increased stresses in the necked portion strongly promote the transformation of V-rich MX carbonitrides into Z-phase with a tetragonal crystal lattice in the studied $9 \% \mathrm{Cr}$ heat-resistant steel with low $\mathrm{Ni}$ content. Moreover, the complete replacement of V-rich MX carbonitrides by Z-phase occurs in the necked portion \#3 adjacent to fracture surface. Extensive necking takes place at low value of remnant creep life-time and, therefore, the full transformation of V-rich MX carbonitrides into Z-phase could insignificantly deteriorate the creep strength of the $9 \% \mathrm{Cr}$ steel. The present steel and P91 steel [27] with low $\mathrm{Ni}$ content are unique materials, in which the formation of Z-phase is highly accelerated by a creep strain/increased stress in the necked
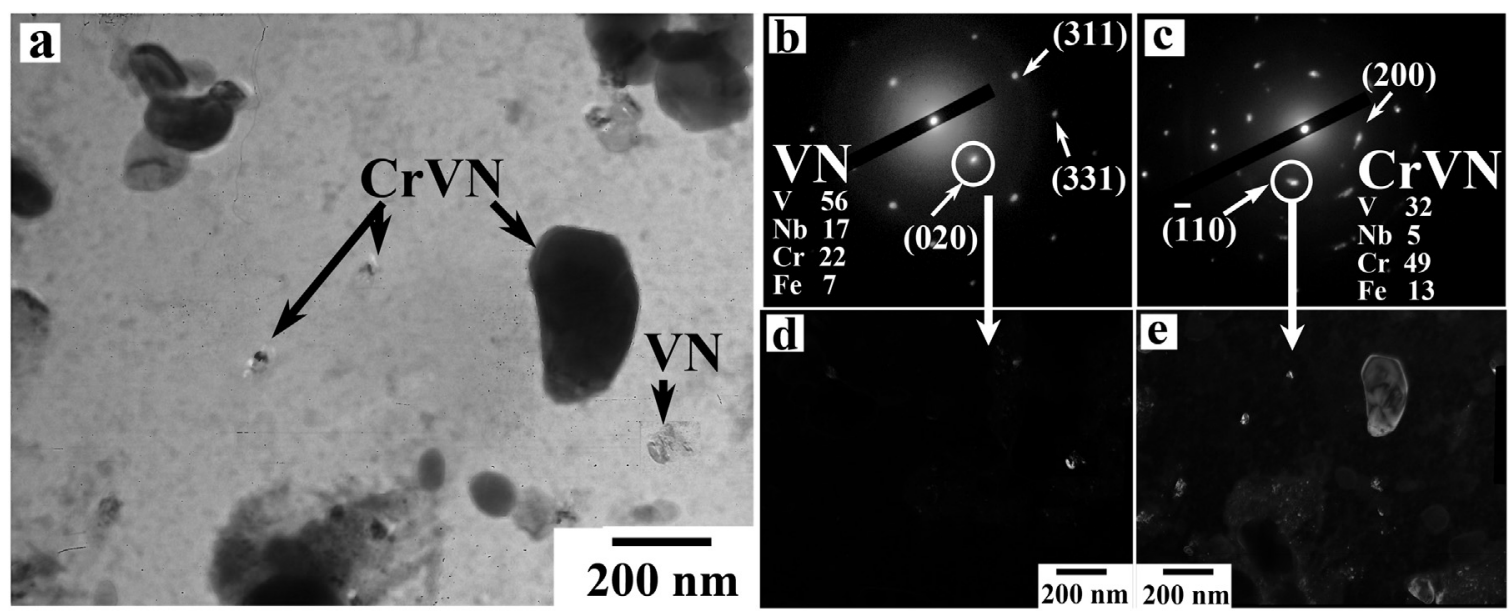

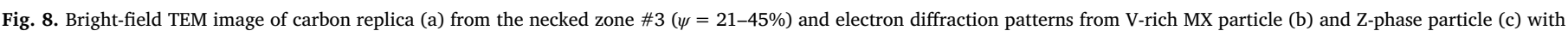
corresponding dark-field images in reflection of VN phase (d) and $\mathrm{CrVN}$ phase (e). Chemical composition of particles is in wt\%. 

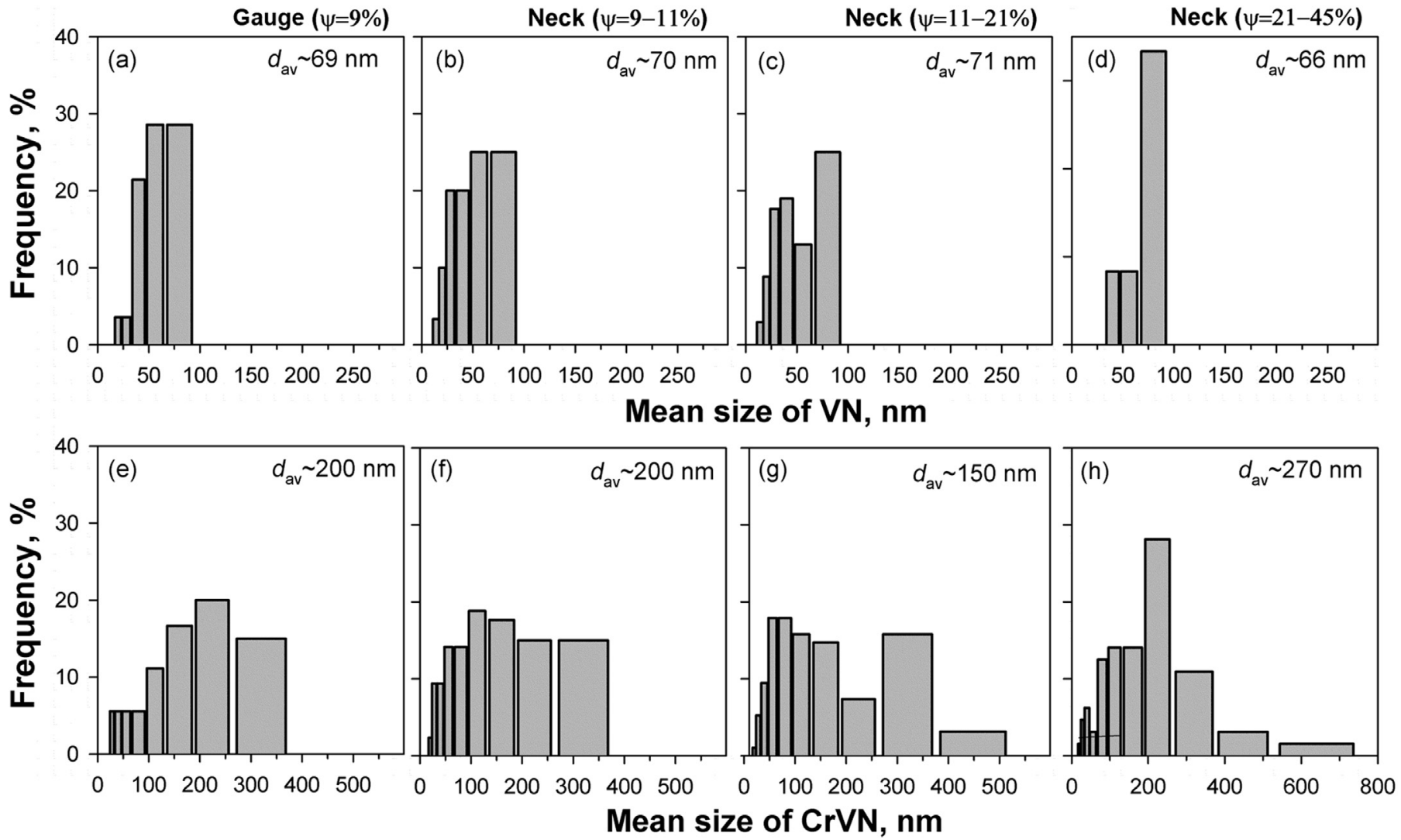

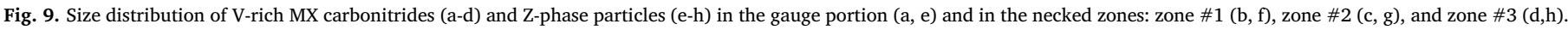

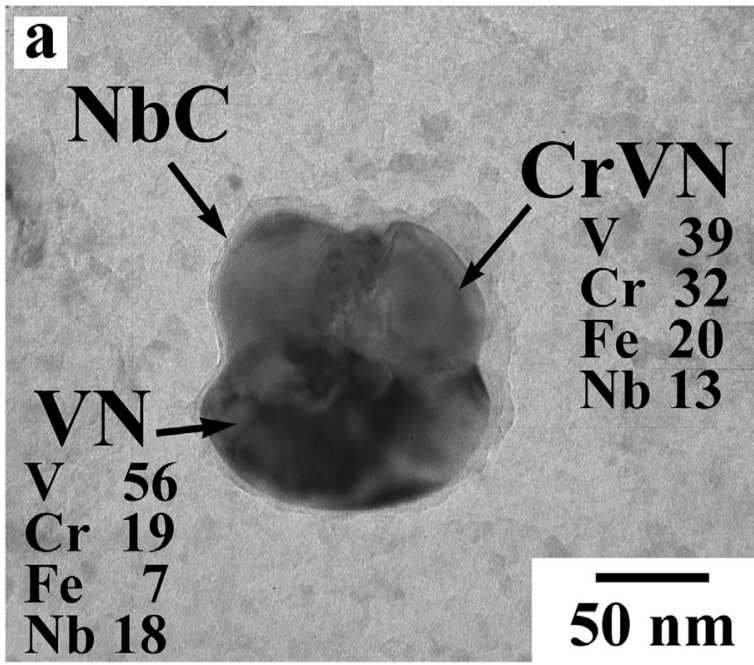

(f) Formation of the nucleus of the $Z$-phase

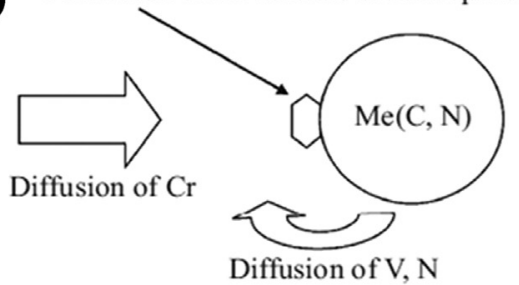

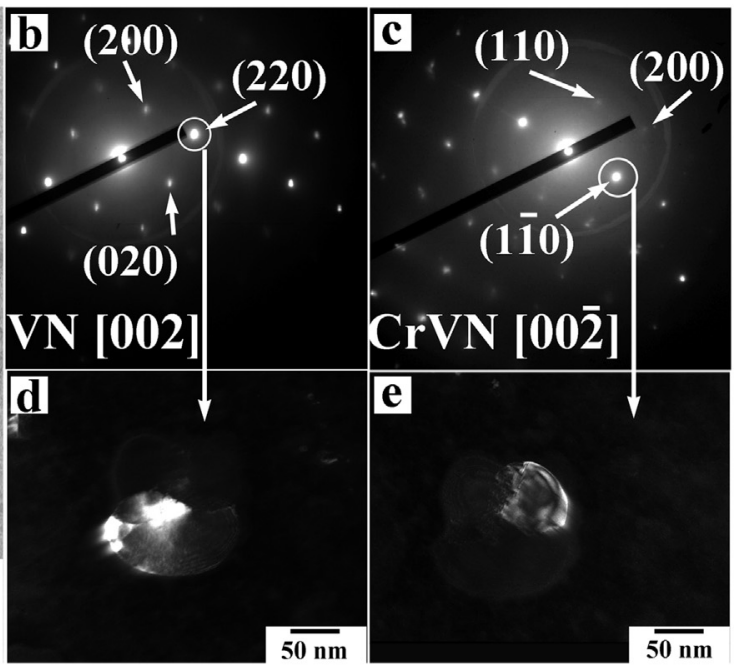

(g)

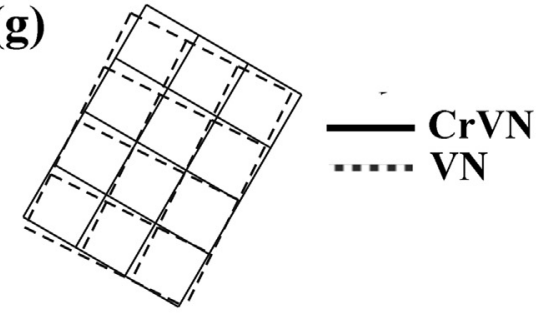

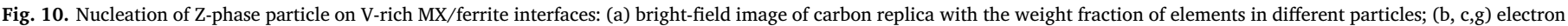

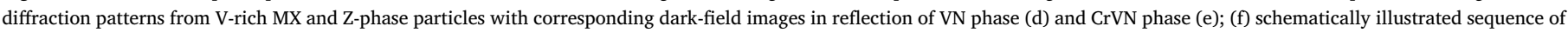
the formation of Z-phase particle with a dimension $\leq 50 \mathrm{~nm}$ taken from [10]. 
portion, in contrast to the P91 steels with $0.28 \mathrm{wt} \% \mathrm{Ni}$ [22].

Two different mechanisms of Z-phase formation have to be discussed in the present study. The first mechanism is the strain-assisted in situ transformation starting from the rim zones of coarse V-rich MX particles towards their core. Coherency of MX interfaces and, therefore, low interfacial energy is provided by the Baker-Nutting orientation relationships between MX carbonitrides and ferrite [1,18,25],

$\{100\}_{\mathrm{MX}}\left\|\{100\}_{\alpha-\mathrm{Fe}},<001>_{\mathrm{MX}}\right\|<011>_{\alpha-\mathrm{Fe}}$

MX carbonitrides exhibiting these orientation relationships are highly resistant to coarsening $[18,21]$. However, the coarsening behavior of V-rich MX particles during first $\sim 50 \mathrm{~h}$ of creep/aging is described by an increase in the interfacial energy up to $0.88 \mathrm{~J} \mathrm{~m}^{-2}$ [29] that leads to a loss of their original orientation relationship. The fine $\mathrm{CrNbN}$ and $\mathrm{CrTaN}$ particles evolved under long-term aging in $12 \% \mathrm{Cr}$ steels may have amorphous layers on their Z-phase/ferrite interfaces as suggested by Danielsen et al. $[15,28]$. The formation of such amorphous layers provides a decrease in the interfacial energy. The surplus energy is stored in the two amorphous/ferrite and amorphous/Z-phase interfaces and may be lower than the energy of a Z-phase/ferrite interface. In addition, a large accommodation strain is required. Under static aging and creep, the thin amorphous shell provides a low interfacial energy and accommodates the large misfit between the Z-phase and ferrite lattices $[15,28]$. However, amorphous layers around V-rich particles which have a Baker-Nutting relationship with low-misfit to the matrix were not observed in [28]. Analysis of the coarsening behavior of V-rich MX particles in the present study and in the previous work [29] shows that the formation of amorphous layers on incoherent V-rich MX/ferrite interfaces could be expected. The formation of the Zphase rim leads to the formation of fully incoherent Z-phase/ferrite interface with a high interfacial energy.

Under creep conditions, the V-rich MX carbonitrides effectively pin gliding dislocations [30]. The shearing of MX carbonitrides may occur, if these dispersoids have a thickness less than $5 \mathrm{~nm}$ [31]. Therefore, the MX dispersoids with dimensions above $10 \mathrm{~nm}$ are non-shearable. MX dispersoids grow under long-term aging in accordance with the wellknown Gibbs-Thomson schema [32]. The interaction between dislocations and dispersoids leads to the creation of additional short-circuits diffusion paths for solutes, such as $\mathrm{Cr}$ and V. This interaction promotes both the formation of a Z-phase rim in V-rich MX dispersoids and the rapid coarsening of Z-phase particles during creep (Fig. 9). The coarsening rate of the Z-phase rim is controlled by the Cr diffusion flux from the ferrite matrix $[14,15]$ and the $\mathrm{V}$ diffusion flux from the V-rich MX core. The formation of a continuous Z-phase rim as a pure CrVN nitride blocks or strongly hinders C depletion of the core $[14,15]$. As a result, despite extensive coarsening, the "hybrid" particles retain their twophase structure consisting of MX core and Z-phase rim.

The presence of Z-phase particles with the size less than V-rich MX carbonitrides as shown in Fig. 9(c) and (d) suggests that the fine V-rich MX carbonitrides with dimensions below $50 \mathrm{~nm}$ transform to Z-phase through another mechanism, which is associated with the Z-phase nucleation on the MX/ferrite semi-coherent interfaces (Fig. 10). It is seem that fine V-rich MX carbonitrides with dimensions below $50 \mathrm{~nm}$ may retain semi-coherent interfaces. An increasing the creep stresses due to necking formation facilitates of the dislocation glide and promotes attractive interaction between dislocations and dispersoids. These interactions create easy short-circuits diffusion paths for solutes, such as $\mathrm{Cr}$, $\mathrm{V}$ and $\mathrm{N}$, around V-rich MX particles that promotes the nucleation and growth of Z-phase on the interfaces of V-rich MX carbonitrides (Fig. 10). Then, the growth of Z-phase particles is accompanied with a complete dissolution of the fine V-rich MX particles. This mechanism of Z-phase formation is characterized by the following orientation relationships between the V-rich MX carbonitride and Z-phase particles.

$(1 \overline{1} 0)_{\mathrm{CrVN}}\left\|(020)_{\mathrm{VX}},[00 \overline{2}]_{\mathrm{CrVN}}\right\|[002]_{\mathrm{VX}}$

This orientation relationship leads to the semi-coherent Z-phase/ ferrite interface. The orientation relationship between the ferrite and Zphase can be written as

$(1 \overline{1} 0)_{\mathrm{CrVN}}\left\|(011)_{\alpha-\mathrm{Fe}},[00 \overline{2}]_{\mathrm{CrVN}}\right\|[011]_{\alpha-\mathrm{Fe}}$

Thus, two different mechanisms of creep strain-assisted Z-phase formation operate in the $9 \% \mathrm{Cr}$ steel during creep at elevated temperature. Such concurrent operation of two mechanisms of Z-phase formation leads to a bimodal particle size distribution (Fig. 9(g)), which accelerates the particle coarsening [33]. The avalanche-like growth of coarse Z-phase particles, therefore, can be attributed to the formation of fine Z-phase particles according to the mechanism of semi-coherent interface nucleation on the substrate from VX particles leading to a large difference between very fine and very coarse particles.

\section{Conclusions}

1. The strain-induced transformation of V-rich MX into Z-phase occurs in a $3 \%$ Co-modified P92-type steel after creep at $650{ }^{\circ} \mathrm{C}$ and an applied stress of $100 \mathrm{MPa}$ with the rupture time of $11,151 \mathrm{~h}$. Increasing plastic deformation strongly promotes this transformation. Two different mechanisms of the Z-phase formation were found to be operative.

2. In situ V-rich $\mathrm{MX} \rightarrow \mathrm{Z}$-phase transformation is the first mechanism providing the formation of coarse "hybrid" Z-phase particles consisting of V-rich MX core and Z-phase rim regions. "Hybrid" particles replace coarse V-rich $\mathrm{MX}$ dispersoids and are susceptible to extensive coarsening. This mechanism is operative in the entire gauge length of the crept specimen.

3. The second mechanism of Z-phase precipitation occurs through the nucleation of fine Z-phase particles on V-rich MX/ferrite interfaces that leads to the replacement of V-rich MX carbonitrides with dimensions $\leq 50 \mathrm{~nm}$ by fine Z-phase particles. The orientation relationship between the V-rich MX carbonitride and Z-phase described by

$(1 \overline{1} 0)_{\mathrm{CrVN}}\left\|(020)_{\mathrm{VX}},[00 \overline{2}]_{\mathrm{CrVN}}\right\|[002]_{\mathrm{VX}}$

causes a small mismatch on the Z-phase/ferrite interfaces. This mechanism is operative only in the zone of extensive necking and leads to avalanche-like growth of the Z-phase particles.

\section{Acknowledgments}

This study was financially supported by the Ministry of Education and Science of Russian Federation, under project of Government Task No. 11.2868.2017/PCh. The authors are grateful to Dr. V. Skorobogatykh and Dr. I. Shchenkova, Central Research Institute for Machine-Building Technology, for supplying the test material. The authors are grateful to Dr. A. Belyakov, Belgorod National Research University, for fruitful discussion of results. TEM analysis was performed by using an equipment at the Joint Research Center, "Technology and Materials", Belgorod National Research University.

\section{References}

[1] F. Abe, T.-U. Kern, R. Viswanathan, Creep-Resistant Steels, Woodhead Publishing, Cambridge, 2008

[2] A. Kostka, K.-G. Tak, R.J. Hellmig, Y. Estrin, G. Eggeler, On the contribution of carbides and micrograin boundaries to the creep strength of tempered martensite ferritic steels, Acta Mater. 55 (2007) 539-550.

[3] F. Abe, Analysis of creep rates of tempered martensitic 9\% Cr steel based on microstructure evolution, Mater. Sci. Eng. A 510-511 (2009) 64-69.

[4] N. Dudova, A. Plotnikova, D. Molodov, A. Belyakov, R. Kaibyshev, Structural changes of tempered martensitic $9 \% \mathrm{Cr}-2 \% \mathrm{~W}-3 \% \mathrm{Co}$ steel during creep at $650{ }^{\circ} \mathrm{C}$, Mater. Sci. Eng. A 534 (2012) 632-639.

[5] V. Dudko, A. Belyakov, D. Molodov, R. Kaibyshev, Microstructure evolution and pinning of boundaries by precipitates in a 9pctCr heat resistant steel during creep, Metall. Mater. Trans. A 44 (2013) S162-S172.

[6] I. Fedorova, A. Kipelova, A. Belyakov, R. Kaibyshev, Microstructure evolution in an advanced 9\% Cr martensitic steel during creep at $923 \mathrm{~K}$ (650 C), Metall. Mater. 
Trans. A 44 (2013) S128-S135.

[7] A.E. Fedoseeva, P.A. Kozlov, V.A. Dudko, V.N. Skorobogatykh, I.A. Shchenkova, R.O. Kaibyshev, Microstructural changes in steel 10Kh9V2MFBR during creep for $40000 \mathrm{~h}$ at $600{ }^{\circ} \mathrm{C}$, Phys. Met. Metallogr. 116 (2015) 1047-1056.

[8] F. Abe, V. Taneike, K. Sawada, Alloy design of creep resistant 9Cr steel using a dispersion of nano-sized carbonitrides, Int. J. Press. Vessels Pip. 84 (2007) 3-12.

[9] K. Suzuki, S. Kumai, Y. Toda, H. Kushima, K. Kimura, Two-phase separation of primary MX carbonitrides during tempering in creep resistant 9 Cr1MoVNb steel, ISIJ Int. 43 (2003) 1089-1094.

[10] R. Kaibyshev, V. Skorobogatykh, I. Shchenkova, Formation of the Z-phase and prospects of martensitic steels with $11 \% \mathrm{Cr}$ for operation above $590^{\circ} \mathrm{C}$, Met. Sci. Heat Treat. 52 (2010) 90-99.

[11] A. Fedoseeva, N. Dudova, R. Kaibyshev, Creep strength breakdown and microstructure evolution in a 3\%Co modified P92 steel, Mater. Sci. Eng. A 654 (2016) $1-12$.

[12] A. Fedoseeva, N. Dudova, R. Kaibyshev, Effect of tungsten on a dispersion of M(C,N) carbonitrides in 9\% Cr steels under creep conditions, Trans. Indian Inst. Met. 69 (2016) $211-215$

[13] H.K. Danielsen, P.E. Di Nunzio, J. Hald, Kinetics of Z-phase precipitation in 9 to 12 pct Cr steels, Metall. Mater. Trans. A 44 (2013) 2445-2452.

[14] L. Cipolla, H.K. Danielsen, D. Venditti, P.E. Di Nunzio, J. Hald, M.A.J. Somers, Conversion of MX nitrides to Z-phase in a martensitic 12\% Cr steel, Acta Mater. 58 (2010) 669-679.

[15] H.K. Danielsen, Review of Z phase precipitation in 9-12 wt\%Cr steels, Mater. Sci. Technol. 32 (2016) 126-137.

[16] H.K. Danielsen, J. Hald, A thermodynamic model of the Z-phase $\mathrm{Cr}(\mathrm{V}, \mathrm{Nb}) \mathrm{N}$, Calphad 31 (2007) 505-514.

[17] A.I. Gusev, A.A. Rempel, A.J. Magerl, Disorder and Order in Strongly Nonstoichiometric Compounds: Transition Metal Carbides, Nitrides and Oxides, 1st ed., Springer, Heidelberg, Germany, 2010.

[18] M. Taneike, K. Sawada, F. Abe, Effect of carbon concentration on precipitation behavior of M23C6 carbides and MX carbonitrides in martensitic 9Cr steel during heat treatment, Metall. Mater. Trans. A 35 (2004) 1255-1262.

[19] M. Yoshizawa, M. Igarashi, K. Moriguchi, A. Iseda, H. Ghassemi-Armaki, K. Maruyama, Effect of precipitates on long-term creep deformation properties of P92 and P122 type advanced ferritic steels for USC power plants, Mater. Sci. Eng. A
510-511 (2009) 162-168.

[20] K. Sawada, K. Suzuki, H. Kushima, M. Tabuchi, K. Kimura, Effect of tempering temperature on Z-phase formation and creep strength in 9Cr-1Mo-V-Nb-N steel, Mater. Sci. Eng. A 480 (2008) 558-563.

[21] A. Fedoseeva, N. Dudova, R. Kaibyshev, Creep behavior and microstructure of a 9Cr-3Co-3W martensitic steel, J. Mater. Sci. 52 (2017) 2974-2988.

[22] K. Sawada, H. Kushima, M. Tabuchi, K. Kimura, Effect of creep deformation on Z phase formation in Gr.91 steel, Mater. Sci. Technol. 30 (2014) 12-16.

[23] K. Sawada, H. Kushima, T. Hara, M. Tabuchi, K. Kimura, Heat-to-heat variation of creep strength and long-term stability of microstructure in Grade 91 steels, Mater. Sci. Eng. A 597 (2014) 164-170.

[24] M.-Y. Kim, S.-M. Hong, K.-H. Lee, W.-S. Jung, Y.-S. Lee, Y.-K. Lee, J.-H. Shim, Mechanism for Z-phase formation in $11 \mathrm{CrMoVNbN}$ martensitic heat-resistant steel, Mater. Charact. 129 (2017) 40-45.

[25] A. Fedoseeva, N. Dudova, U. Glatzel, R. Kaibyshev, Effect of W on tempering behaviour of a 3\%Co modified P92 steel, J. Mater. Sci. 51 (2016) 9424-9439.

[26] H.K. Danielsen, J. Hald, On the nucleation and dissolution process of Z-phase Cr $(\mathrm{V}, \mathrm{Nb}) \mathrm{N}$ in martensitic 12\%Cr steels, Mater. Sci. Eng. A 505 (2009) 169-177.

[27] C.G. Panait, W. Bendick, A. Fuchsmann, A.-F. Gourgues-Lorenzon, J. Besson, Study of the microstructure of the Grade 91 steel after more than $100,000 \mathrm{~h}$ of creep exposure at $600^{\circ} \mathrm{C}$, Int. J. Press. Vessels Pip. 87 (2010) 326-335.

[28] H.K. Danielsen, S. Kadkhodazadeh, F.B. Grumsen, M.A.J. Somers, New amorphous interface for precipitate nitrides in steel, Philos. Mag. 94 (2014) 2339-2349.

[29] A. Fedoseeva, N. Dudova, R. Kaibyshev, Effect of alloying on interfacial energy of precipitation/matrix in high-chromium martensitic steels, J. Mater. Sci. 52 (2017) 4197-4209.

[30] V. Dudko, A. Belykov, R. Kaibyshev, Evolution of lath substructure and internal stresses in a 9\% Cr steel during creep, ISIJ Int. 57 (2017) 540-549.

[31] L. Tan, T.S. Byun, Y. Katoh, L.L. Snead, Stability of MX-type strengthening nanoprecipitates in ferritic steels under thermal aging, stress and ion irradiation, Acta Mater. 71 (2014) 11-19.

[32] D.A. Porter, K.E. Esterling, M. Sherif, Phase Transformation in Metals and Alloys, third ed., CRS Press, 2009.

[33] A. Schneider, G. Inden, Simulation of the kinetics of precipitation reactions in ferritic steels, Acta Mater. 53 (2005) 519-531. 